Research Article

\title{
Manufacturing of Ecofriendly Bricks Using Microdust Cotton Waste
}

\author{
Mebrahtom Teklehaimanot $\mathbb{D}^{1},{ }^{1}$ Haregeweyni Hailay, ${ }^{2}$ and Tamrat Tesfaye $\mathbb{D D}^{3}$ \\ ${ }^{1}$ Department of Garment and Textile Engineering, Ethiopian Institute of Technology, Mekelle University, Mekelle, Ethiopia \\ ${ }^{2}$ Faculty of Textile and Fashion Technology, Aksum Institute of Technology, Aksum University, Axum, Ethiopia \\ ${ }^{3}$ Ethiopian Institute of Textile and Fashion Technology, Bahir Dar University, Bahir Dar, Ethiopia
}

Correspondence should be addressed to Mebrahtom Teklehaimanot; mebreat@gmail.com

Received 21 September 2020; Accepted 27 April 2021; Published 8 May 2021

Academic Editor: Amiya K. Jana

Copyright (c) 2021 Mebrahtom Teklehaimanot et al. This is an open access article distributed under the Creative Commons Attribution License, which permits unrestricted use, distribution, and reproduction in any medium, provided the original work is properly cited.

\begin{abstract}
Large amounts of cotton microwastes are accumulated in textile industries. The cotton microdust is less to ignite and causes serious environmental problems and health hazards. This paper presents an experimental study, which investigates the potential use of cotton microdust to produce new and lightweight brick for construction industries. The physical and mechanical properties of brick mixes having different levels of cotton microdust ratio were investigated. The test results recorded for compressive strength, unit weight, and water absorption values satisfy the relevant required standards for normal construction bricks. The results show that the replacement of clay soil and cement by cotton microdust does not exhibit a sudden brittle fracture even beyond the failure loads, indicates high energy absorption capacity, reduces the unit weight dramatically, and introduces smother surface compared to the current concrete bricks in the market. The results also show that usage of cotton microdust with different mixing ratios for bricks will give light-weight composite, and brick could be an economical alternative to be used for partition of board concrete blocks and sound barrier panels.
\end{abstract}

\section{Introduction}

Brick is a building material used to make walls, pavements, and other elements in masonry construction. Since the large demand has been placed on building material, especially in the last decade, owing to the increasing population, which causes a chronic shortage of building materials, people have been challenged to convert the industrial wastes to useful materials such as building and construction materials. Accumulation of unmanaged wastes in developing countries increased environmental concern.

Recycling of such wastes as building materials appears to be a viable solution not only to such pollution problem but also to the problem of economical design of buildings. In spinning and fabric manufacturing processes, dust and fly generated from the industry is a major health hazard for the people working inside the textile industry. Cotton microdust exists in almost all sections of spinning mills; however, blow rooms and carding sections have the highest risk of exposure. A study has revealed that more than one fourth of the workers of those sections are facing cotton dust caused diseases regularly. Cotton in its whole processing value chain can generate potential health hazards.

The generation of microdust causes chronic coughs and, sometimes, even bronchitis to the workers who are severely exposed to them. Cotton microdusts can produce brick that could be used as a construction material. Due to the demand of bricks as a building material, many researchers have investigated the potential wastes that can be recycled or incorporated as an additive in the manufacturing process of bricks. Previous research studies [1-3] provided the possible utilization of industrial wastes in various forms of concrete production. For instance, the use of waste rubber, glass powder, and paper waste sludge in concrete mix has received considerable attention over the past years.

Some research studies on the textile waste used in concrete mix were carried out in the past, such as the textile waste cuttings [1], the textile effluent treatment plant sludge 
[2], and the cotton stalk fibre. Although these research studies [1-3] using wastes from the textile industry are providing similar and encouraging results, those wastes are dissimilar in behavior than the cotton wastes $(\mathrm{CW})$ which are widely available in large amount from the spinning industry utilized in the presented research. They are mainly used for constructing partitions, and for making a green building, it is important that the material in such construction process should be environmentally friendly. For large production of bricks from waste materials, further research and development is required not only on the technical, economic, and environmental aspects but also on standardization, government policy, and public education related to waste recycling and sustainable development.

Cotton dust is defined as dust present in the air during the handling or processing of cotton, which may contain a mixture of many substances including ground up plant matter, fibre, bacteria, fungi, soil, pesticides, noncotton plant matter, and other contaminants which may have accumulated with the cotton during the growing, harvesting, and subsequent processing or storage periods. Various types of waste materials from the different industries have been used in different proportions, and different methods are adopted to produce bricks [4]. The size of cotton dust particles is shown in Table 1.

In recent years, the several facilities have been proactively locating markets for this waste material. The alternative use of CW fibers includes soil amendment, mulch, briquetting for direct land application, fuel source, and cattle feed on CW [5]. However, these are not officially and widely accepted waste management techniques at the moment. The cotton industries worldwide are expecting to reduce their CW disposal by alternative options for handling this waste as a by-product that has a potential as a multiuse product. Most of the CW used in this research is currently disposed in sanitary landfills or open dumped into uncontrolled waste pits and open areas.

The reuse of waste is meaningful from a variety of viewpoints such as to save and sustain the natural building material resources; to mitigate the pollution caused by stocked waste piles; and to save utilized energy in production processes [6]. The productive reuse of waste material represents a way of solving the major concern of solid waste management [7]. Due to expanding urbanization, poor landfill capacity, and unsuitable burner zones waste disposal, using landfilling techniques become more and more difficult [8]. Therefore, industrial waste and byproducts could be valuable alternative resources for building construction and other applications [9]. Numerous attempts have been made to incorporate industrial waste in the production of bricks. Textile effluent treatment plant sludge, cotton waste, rice husk ash, granulated blast furnace slag, processed waste tea, petroleum effluent treatment plant sludge, craft pulp production residue, and waste paper pulp are used as a raw material for brick production [10]. The partial or full replacement of conventional building materials that may face depletion have compelled engineers to unearth cheaper alternative materials. Recycling of such industrial wastes by blending
TABle 1: Size of cotton dust particles [4].

\begin{tabular}{lc}
\hline Types & Size of the particle $(\mu \mathrm{m})$ \\
\hline Trash & Above 500 \\
Dust & $50-500$ \\
Microdust & $15-50$ \\
Breathable & Below 15 \\
\hline
\end{tabular}

them into building materials is a proficient solution to the pollution problem. Figure 1 shows the pictorial representation of cotton waste and limestone powder.

Accumulation of unmanaged wastes, especially in developing countries, is the cause of environmental concerns. Such concerns can be partially addressed by recycling of such wastes. Converting such wastes into building materials appears to be a viable solution. It not only helps in mitigating the pollution problem but also leads to reduced cost of buildings without compromising on structural strength [11]. The properties of cotton waste, lime powder waste, and cement are illustrated in Table 2.

Using the CW-LPW combination as a fine aggregate in its natural form has allowed economical, lighter, and environmentally friendly new composite material [12]. This paper presents the research work undertaken to study the properties of this new composite material which contains the various levels of CW, cement, sand, gravel, and water. Researchers found from their research work that the various wastes that are currently recycled in brick manufacturing have been reviewed [13]. Research results from this paper report that incorporation of these waste materials in brick manufacturing could enhance performance in terms of making more environmental and an economical brick which neither consumes energy resources nor emits pollutant gases. Moreover, the use of these materials in brick manufacturing could be carried out without firing and becomes a more economical option.

In addition to this, the result from the previous study motivates researchers to find alternative waste resources to develop sustainable construction material. In the undeveloped countries with inadequate resources, it is even more important. Using natural waste materials with low thermal conductivity in building masonry units improves insulation of buildings by providing an energy-efficient solution. The waste from cotton processing is a mixture of stems, leaves, soils, and lint. Also, there are few research studies in converting the proposed waste materials for the production of sustainable construction materials. The aim of this paper is to partially substitute raw materials and enhance the properties of manufactured bricks using cotton waste from textile industries.

\section{Materials and Methods}

2.1. Material. Cotton dust: cotton dust (Figure 2) that contains a mixture of stems, sand, soil, and lint was kindly supplied by Almeda Textile PLC, Adwa, Ethiopia.

Soil: soil (type reddish clay used for brick manufacturing locally) was supplied by brick manufactures in Axum, Ethiopia. 


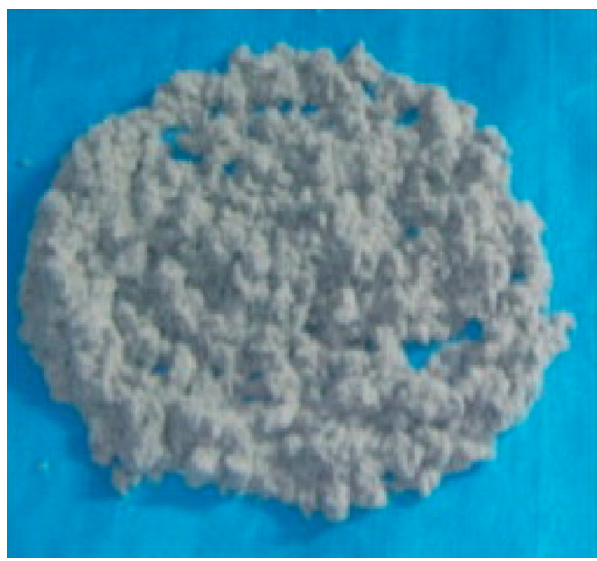

(a)

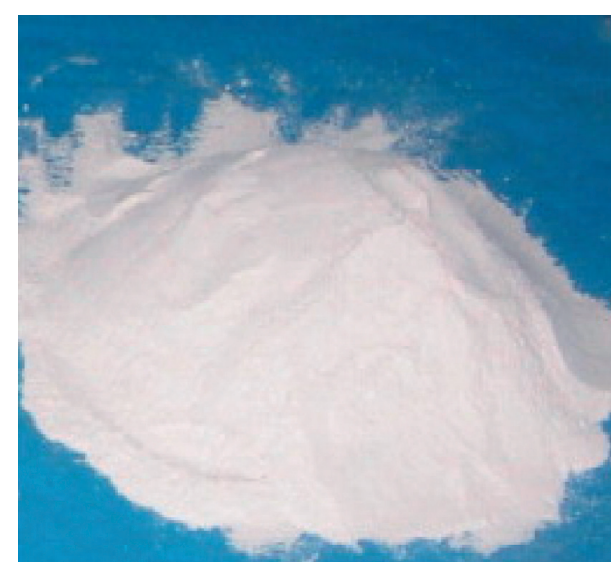

(b)

Figure 1: (a) cotton waste and (b) limestone powder.

TABLE 2: The properties of cotton waste (CW), lime powder waste (LPW), and cement [12].

\begin{tabular}{lccc}
\hline Properties & CW & LPW & Cement \\
\hline $\mathrm{SiO}_{2}(\%)$ & 29.42 & 0.26 & 19.20 \\
$\mathrm{CaO}(\%)$ & 24.35 & 56.19 & 52.00 \\
$\mathrm{MgO}(\%)$ & 0.58 & - & 1.00 \\
$\mathrm{Al}_{2} \mathrm{O}_{3}(\%)$ & 13.89 & 0.25 & 3.70 \\
$\mathrm{Fe}_{2} \mathrm{O}_{3}(\%)$ & 0.46 & 0.30 & 0.16 \\
$\mathrm{SO}_{3}(\%)$ & - & - & 2.80 \\
$\mathrm{Na}_{2} \mathrm{O}(\%)$ & - & - & - \\
$\mathrm{K}_{2} \mathrm{O}(\%)$ & - & - & 0.27 \\
$\mathrm{Cl}(\%)$ & - & - & 0.006 \\
Loss on ignition $(\%)$ & 29.40 & 42.65 & 8.20 \\
Density & 0.5 & 2.67 & 3.00 \\
Specific surface area $\left(\mathrm{m}^{2} / \mathrm{kg}\right)$ & - & 145 & 500 \\
Compressive strength for 28 days $(\mathrm{MPa})$ & - & - & 48 \\
\hline
\end{tabular}

\subsection{Methods}

2.2.1. Brick Sample Production. The brick manufacturing and optimization of process parameters for brick production using waste cotton dust from textile industry were conducted using a research design according to Table 3.

Mix preparation: for this specific study, the required amount of raw materials and additives was measured by using a $24 \mathrm{~cm} \times 12 \mathrm{~cm} \times 6 \mathrm{~cm}$ volume box with different ratios. The amounts of materials were prepared according to ASTM mixing that means $1: 2: 3$ and $1: 2: 2$, where mix ratio $1: 2: 3$ means one part cement to two parts sand and three parts gravel.

In the beginning, the aforementioned raw materials were mixed with water and homogenized with each other in proportion before sample brick preparation (Figure 3(a)). The raw materials have been mixed with enough amount of water to obtain homogeneous and smooth mixture for molding operation. In the mixing process of samples, the clay was mixed till it is observed that CW is uniformly scattered within the mixes. In order to obtain more homogeneous mixes, the water was sprayed by using a water pump onto the mixes while the mixing was carried out. If mixing was performed effectively, it reduces cracking during drying. Afterward, the fresh mixes were fed into the wood molds.
Moulding process: the size of a mold for brick making was selected by considering the shrinkage effect of the clay. Produced brick shrinks during drying, so the chosen mold size was larger than the intended finished brick. For hand molding, the tempered clay was forced in the mold in such a way that it fills all the corners of the mold. Extra clay was removed by using a wooden strike. The mould was then lifted up, and raw brick was left on ground for the drying process (Figure 4).

Drying process: drying was carried out by placing the bricks in sheds with open sides so as to ensure free circulation of air and protection from bad weather and rains. As it is clearly seen in Figure 5, molded bricks have been allowed to dry for 7 to 14 days in such a way that there is no direct contact with sun light.

Burning of bricks: before the firing process, all the moulded brick samples were sun-dried as per the conventional method as shown in Figure 5 for 7-14 days, and most of the water present in the brick samples is evaporated in this process aiming to prevent cracking. Then, the dried brick samples were placed in a burning house for 14 days (Figure 6). All the burnt bricks were allowed to cool down and transferred for characterization to assess and compare the quality of brick produced using cotton waste with the controlled bricks.

2.2.2. Brick Sample Characterization. Compressive strength: the dry compressive strength of brick samples was determined by using the servocontrolled compression test machine with a maximum capacity of $800 \mathrm{KN}$. The compression load was applied onto the face of the sample having the dimensions of $240 \mathrm{~mm} \times 60 \mathrm{~mm}$. The compressive strength was determined by dividing the maximum load with the applied load area of the brick samples. Also, compressive strength was calculated using

$$
\text { Stress }=\frac{\text { Force }}{\text { Area }}
$$

Water absorbency: by taking one sample from each mixed ratio, twelve brick samples with the dimension of $24 \mathrm{~cm} \times 12 \mathrm{~cm} \times 6 \mathrm{~cm}$ were used for the water absorption test. First, the samples were placed on the oven dry at $105^{\circ} \mathrm{C}$ 


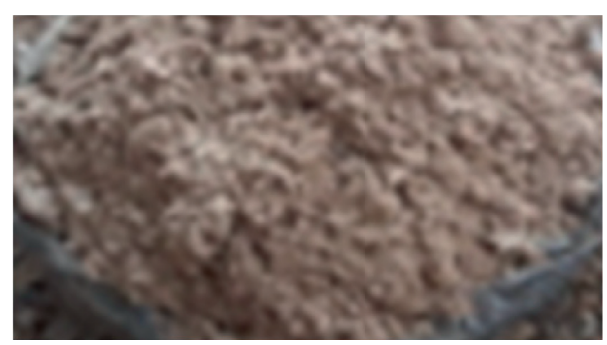

(a)

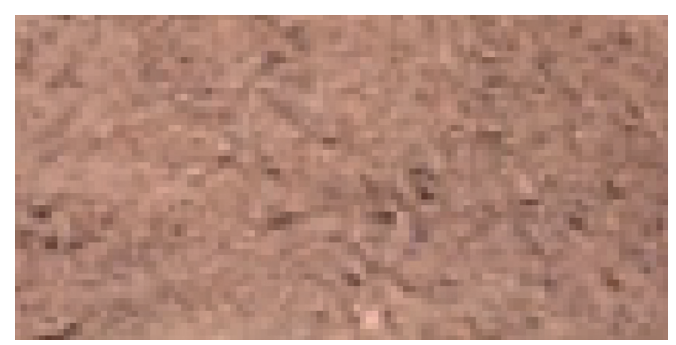

(b)

Figure 2: Cotton microdust (a) and soil (b).

TABle 3: Experimental plan of the brick production using Design Expert 7.0.0.

\begin{tabular}{lcc}
\hline Run & Component A: cotton microdust, \% & Component B: soil, \% \\
\hline 1 & 25.00 & 75.00 \\
2 & 10.00 & 90.00 \\
3 & 0.00 & 100.00 \\
4 & 15.00 & 85.000 \\
5 & 10.00 & 90.00 \\
6 & 0.00 & 100.00 \\
7 & 25.00 & 25.00 \\
8 & 0.00 & 100.00 \\
9 & 5.00 & 95.00 \\
10 & 30.00 & 70.00 \\
11 & 15.00 & 85.00 \\
12 & 30.00 & 70.00 \\
13 & 30.00 & 70.00 \\
\hline
\end{tabular}

in order to remove the existing moisture on the brick till no mass variation is observed. The oven dried bricks were immersed into the water curing tank (water container tank) for 24 hours. Then, the cured samples were wiped using dry cloth to remove the excess water, and the weight of brick after wetting was taken. The water content of samples in percent was calculated using

$$
\text { Water absorbation } \%=W 2-\left(\frac{W 1}{W 2}\right) \times 100,
$$

where $W 1=$ dry weight of the brick and $W 2=$ weight of the brick after wetting.

Mass of the brick sample: the brick samples were cooled at room temperature, and their unit weights were obtained by dividing the mass of the bricks by their overall volume. In this calculation, the unit weight of the brick is directly proportional to the mass of the brick, but inversely proportional to volume. Ten samples were tested for the unit weight test by taking one sample from each mix ratio. The samples have the same volume $24 \mathrm{~cm} \times 12 \mathrm{~cm} \times 6 \mathrm{~cm}$ and different mass depending on their mix percentages.

$$
\text { Unit weight }=\frac{\text { mass }}{\text { volume }} \text {. }
$$

\section{Results and Discussion}

As it is clearly seen in Table 4, a series of experimental tests were carried out to determine the water absorption, unit weight, compressive strength, and weight values of different brick samples. The bricks were manufactured from two different mixing elements. The first mixes were performed to replace cement, and the second mixes were performed to replace the soil clay. In the first case, the colors of the brick were shifted from dark white to dark green as the ratio of cotton increases and the cement content decreases, while for the second one, the brick manufactured from $100 \%$ soil after burning was found with dull red color (Figure 7). But, after mixing with cotton dust and reducing the clay soil, the color of the brick becomes light red.

3.1. Compressive Strength. According to the Indian Standard (IS 3495), the minimum compressive strength of burnt bricks has three classes: first-class bricks: $10.3 \mathrm{MPa}$; secondclass brick: $6.8 \mathrm{MPa}$; and common building brick: $3.4 \mathrm{MPa}$. The ten bricks with different mix ratios have different compressive strengths. From these, the mix ratios of cotton waste and soil samples are preferable compared to the mix ratio of cement, gravel, sand, and cotton waste samples because the samples are burned to get additional strength. The compressive strength test of the produced samples is illustrated in Figure 8.

The observations during the tests show that the effect of $100 \%$ cotton waste does not exhibit a sudden brittle fracture even beyond the failure loads and indicates high energy absorption capacity by allowing lower labouring cost. From this, we can conclude that when the amount of cotton waste increases, the compressive strength of that brick also increases and vice versa. The calculated correlation for the compressive strength of the brick samples is " 1 " (Table 5).

The effect of the amount of cotton dust in the produced brick samples on compressive strength is shown in Figure 9. Result from Figure 9 indicates that as the cotton waste increases from $0 \%$ to $20 \%$ there is a sharp increase in compressive strength properties of the produced brick sample. This could be due to the incorporation of waste cotton fibre in the brick manufacturing process as it enhances the compressive strength property.

As it is shown in Table 6, the factorial model selected is statistically significant. This implies that there is only a $0.01 \%$ chance that a "Model F Value" this large could occur due to noise.

Depending on the abovementioned experimental results for different factors, the following ratios are selected according to the response targets required. 


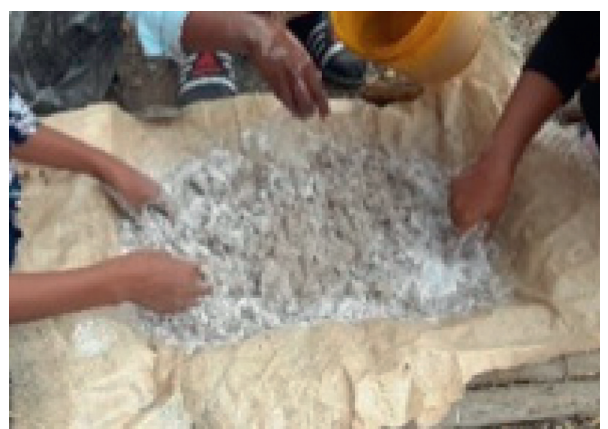

(a)

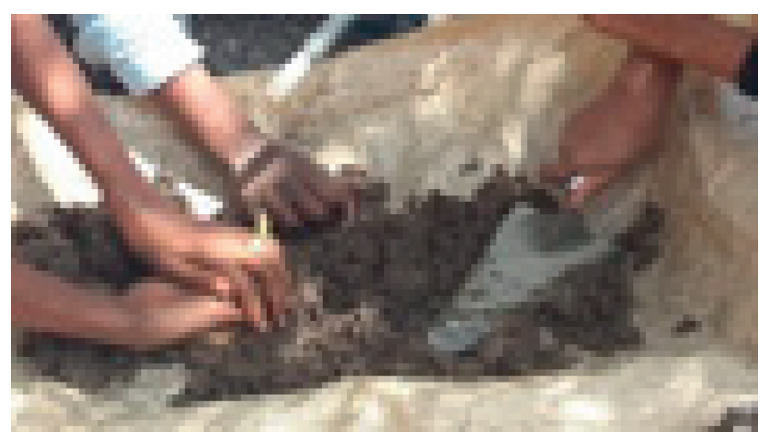

(b)

FIGURE 3: (a) Clay preparation process; (b) mixing of clay process.

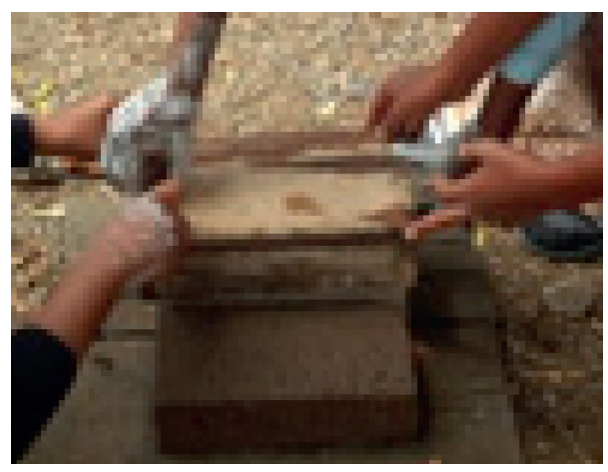

FIgURE 4: Moulding process.

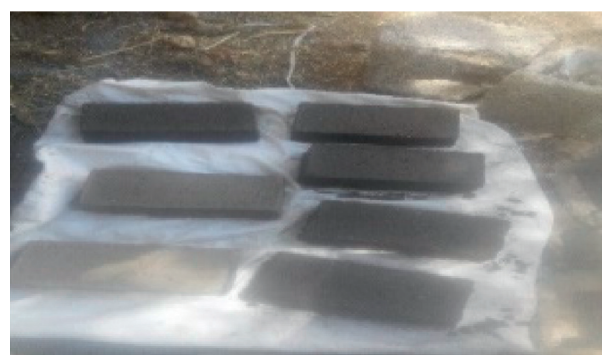

(a)

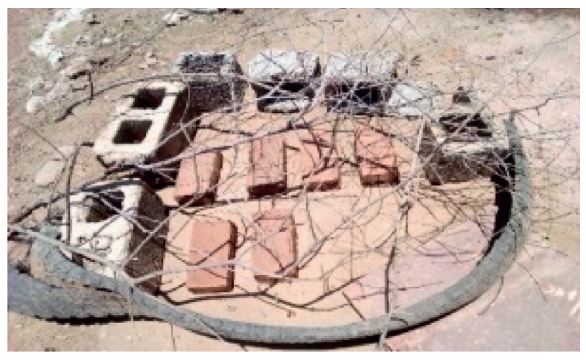

(b)

FIGURE 5: Air drying of the produced brick.
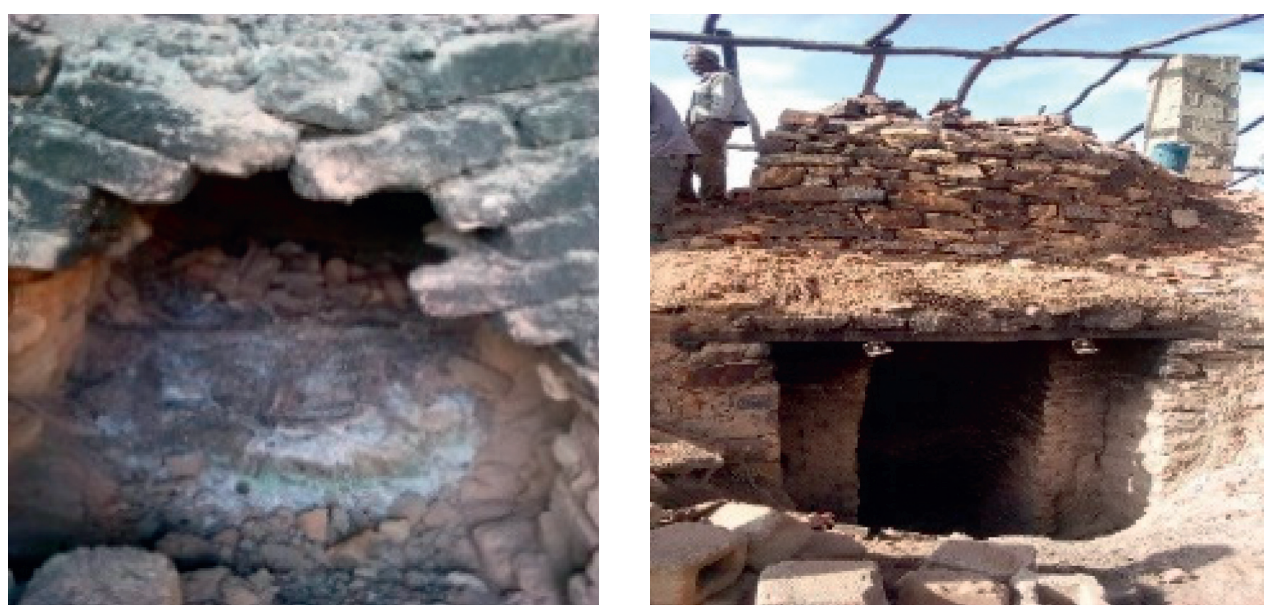

FIGURE 6: Burning process of brick. 
TABLE 4: Experimental test results for compressive strength, water absorption, and mass and unit weight of bricks.

\begin{tabular}{|c|c|c|c|c|c|c|}
\hline Run & $\begin{array}{c}\text { Component } 1 \mathrm{~A} ; \\
\text { dust }(\%)\end{array}$ & $\begin{array}{c}\text { Component } 2 \mathrm{~B} \text {; } \\
\text { soil }\end{array}$ & $\begin{array}{c}\text { Response } 1 \text {, strength } \\
(\mathrm{MPa})\end{array}$ & $\begin{array}{c}\text { Response 2, } \\
\text { absorbency (\%) }\end{array}$ & $\begin{array}{l}\text { Response 3, unit weight } \\
\left(\mathrm{g} / \mathrm{cm}^{3}\right)\end{array}$ & $\begin{array}{l}\text { Response 4; } \\
\text { weight }(\mathrm{kg})\end{array}$ \\
\hline 1 & 25.00 & 75 & 6.562 & 9.4397 & 1.2025 & 2.095 \\
\hline 2 & 10.00 & 90.00 & 6.087 & 6.687 & 1.4388 & 2.548 \\
\hline 3 & 0.00 & 100.00 & 6.599 & 5 & 1.55 & 2.61 \\
\hline 4 & 15.00 & 85.00 & 6.259 & 7.1907 & 1.3469 & 2.37 \\
\hline 5 & 10.00 & 90.00 & 6.0799 & 6.699 & 1.4299 & 2.52 \\
\hline 6 & 0.00 & 100.00 & 6.677 & 5.013 & 1.539 & 2.6599 \\
\hline 7 & 25.00 & 75.00 & 6.562 & 9.4397 & 1.2025 & 2.095 \\
\hline 8 & 0.00 & 100.00 & 6.087 & 5.012 & 1.541 & 2.599 \\
\hline 9 & 5.00 & 95.00 & 6.382 & 5.85 & 1.4889 & 2.6304 \\
\hline 10 & 30.00 & 70.00 & 6.7 & 11.2 & 1.2 & 1.899 \\
\hline 11 & 15.00 & 85.00 & 6.263 & 7.21 & 1.355 & 2.355 \\
\hline 12 & 30.00 & 70.00 & 6.795 & 11.199 & 1.19 & 1.95 \\
\hline 13 & 30.00 & 70.00 & 6.693 & 11.185 & 1.15 & 1.9975 \\
\hline
\end{tabular}

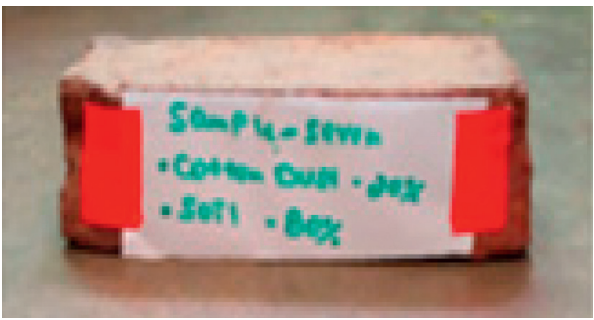

(a)

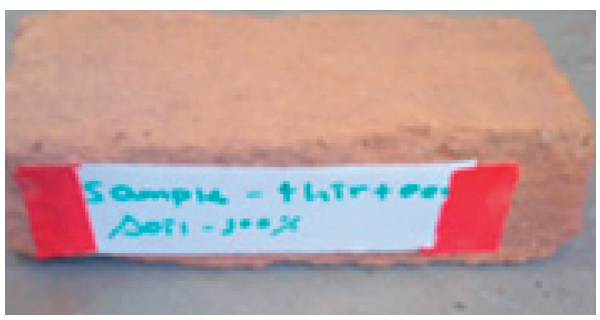

(c)

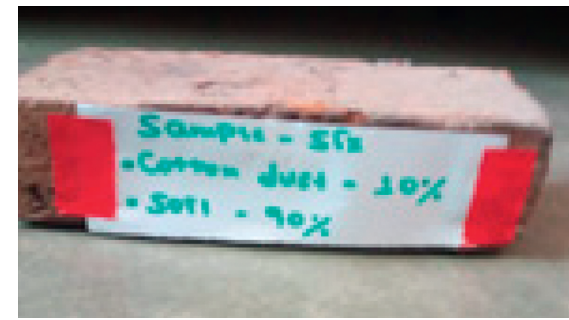

(b)

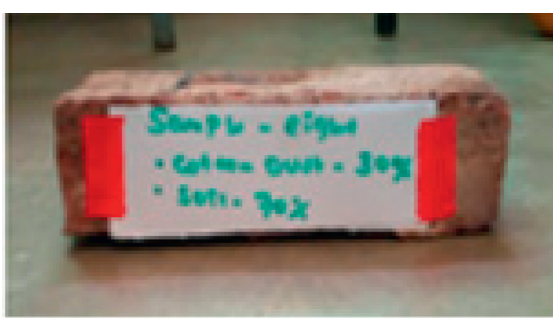

(d)

FIGURE 7: Brick samples manufactured from different mixing ratios. (a) 20\% cotton waste and $80 \%$ soil; (b) $10 \%$ cotton waste and $90 \%$ soil; (c) $100 \%$ soil; and (d) $30 \%$ cotton waste and $70 \%$ soil.
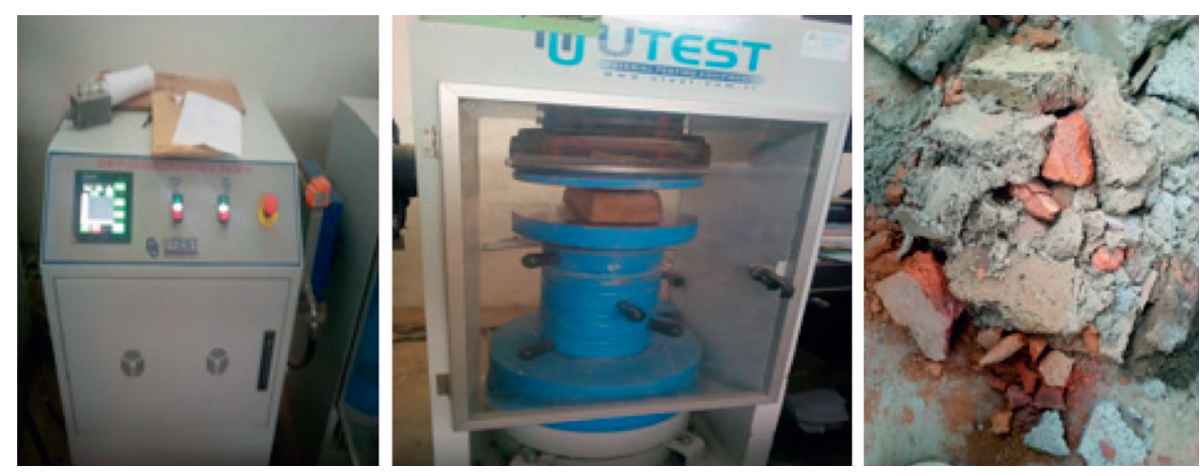

FIgURE 8: Compressive strength testing of brick.

TABLE 5: Correlation data analysis for compressive strength of brick samples.

\begin{tabular}{lcc}
\hline & Cotton dust (\%) & Compressive strength (MPa) \\
\hline Cotton dust (\%) & 1 & - \\
Compressive strength $(\mathrm{MPa})$ & 0.948356 & 1 \\
\hline
\end{tabular}




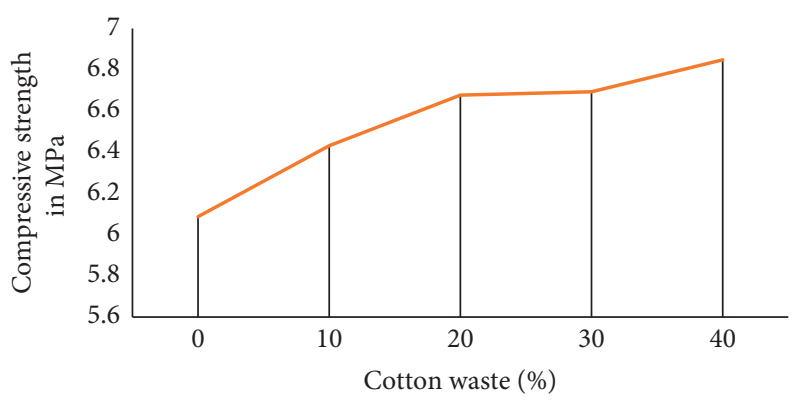

FIGURE 9: Effect of cotton microdust ratio on brick strength.

TABLE 6: ANOVA analysis of compressive strength of bricks.

\begin{tabular}{|c|c|c|c|c|c|c|}
\hline \multirow[t]{2}{*}{ Forced terms } & \multicolumn{6}{|c|}{ A- dust and B- soil, model- linear mixture } \\
\hline & Sum of square & $\mathrm{df}$ & Mean square & F value & $p$ value prob $>p$ & - \\
\hline Source & 0.013 & 2 & $6.578 \mathrm{E}-003$ & 9.79 & $<0.0044$ & Significant \\
\hline & 0.10 & 1 & $5.118 \mathrm{E}-003$ & 7.62 & $<0.0201$ & - \\
\hline $\mathrm{AB}$ & $3.284 \mathrm{E}-003$ & 1 & $8.038 \mathrm{E}-003$ & 11.79 & $<0.0061$ & - \\
\hline
\end{tabular}

3.2. Water Absorbency. The water absorption of the blank sample (100\% cotton dust) is extremely higher. This is an expected result owing to the water absorption nature of cotton waste. As shown in Table 4, when the mix percentage of cotton waste increases, the water absorption also increases due to higher moisture absorption characteristics of cotton. According to the Indian Standard (IS 3495), water absorption of bricks after 24 hours immersion has three classes: first-class bricks, should not be more than 15\%; second-class bricks, should not be more than 20\%; and third-class bricks, should not be more than $25 \%$. The test results in Table 5 show that the water absorption of the conventional brick (100\% soil) is less than that of the bricks with cotton dust mixture at different ratios. Compared to the blank sample, the $100 \%$ cotton dust sample has an extremely high water absorption value. Also, in general, as the cotton dust increases, the water absorption also increases. The water absorption of any bricks shall not be more than $20 \%$ [6]. In the current study, the water absorption properties of the bricks lie in the range between $5-12 \%$ in all mix ratios.

To know the effect of cotton waste on the water absorption property of brick, we use correlation data analysis. The correlation data analysis shows the relationship between the percent of cotton waste with water absorption (Table 7). If the result is " 1 ," they have a direct relationship. In this case, if one factor increases, the other also increases and vice versa. If the result is " -1 ," the factors have an inverse relationship, and if it is " 0 ," there is no correlation.

The relationship between the amount of cotton waste in the bricks with the water absorption is shown in Figure 10. From the test result values and the norms for constriction bricks for the water absorption value, the produced bricks can categorized as first-grade bricks. But, the end use of bricks is versatile and recommended water absorption may depend on its end use. Especially, bricks needed for water pool, roads, or walls exposed to continuous water touch need special treatment and values. As it is clearly seen in Figure 10, the moisture absorption of the composite increases as cotton dust percentage increases. From these results, it can be concluded that $40 \%$ replacement of soil clay using cotton waste could be possible if the composite is targeted to be used as partitions and interior building construction material.

As it is shown in Table 8, the factorial model selected is statistically significant. This implies that there is only a $0.01 \%$ chance that a "Model F Value" this large could occur due to noise.

3.3. Mass of the Brick Sample. The mass of brick is also related with the amount of cotton waste mix percentage (Table 9). For example, when the mass of the blank sample is compared with the other mix ratios, samples that contain more cotton waste are lighter. Using the correlation data analysis, the cotton dust percentage and mass of bricks are inversely correlated. The calculated correlation is " -1 ," so as the percent of cotton dust increases, the mass of the brick also decreases.

The relationship between the amount of cotton dust in the brick and the weight of brick is shown in Figure 11. As it is clearly seen in Figure 11, the mass of the brick reduces as the cotton mix ratio increases; this could be due to the lighter weight of cotton waste compared to lime powder waste and cement (Table 2).

As it is shown in Table 10, the factorial model selected is statistically significant. This implies that there is only a $0.01 \%$ chance that a "Model F Value" this large could occur due to noise.

3.4. Unit Weight of Bricks. As it is clearly seen in Table 4, as the percentage of cotton increases in the mix, the density of the bricks reduces; this could be due to lighter weight of waste cotton. When the mass of the blank sample is compared with the other mix ratios, the sample that contains more cotton waste is lighter. As it is shown in Table 11, the factorial model selected is statistically significant. This implies that there is only a $0.01 \%$ chance that a "Model F Value" this large could occur due to noise. 
TABLE 7: Correlation analysis for water absorption of brick samples.

\begin{tabular}{lcc}
\hline & Cotton dust \% & Water absorption (\%) \\
\hline Cotton dust (\%) & 1 & - \\
Water absorption (\%) & $\mathbf{0 . 9 3 7 2 1 3 7 2 5}$ & 1 \\
\hline
\end{tabular}

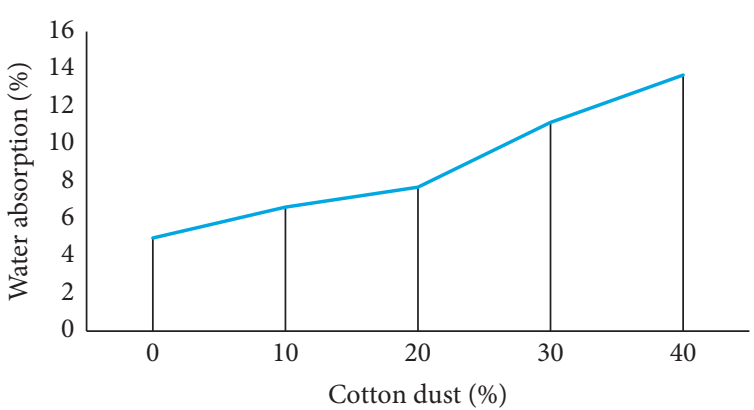

FIgURE 10: The effect of cotton dust on moisture absorption of the produced composite.

TABLE 8: ANOVA (analysis of variance) of bricks for water absorption.

\begin{tabular}{lcccccc}
\hline Forced terms & \multicolumn{5}{c}{ A- dust, B- soil, model: linear mixture } \\
\hline \multirow{3}{*}{ Source } & Sum of square & $\mathrm{df}$ & Mean square & F value & $p$ value & - \\
& 2.22 & 2 & 1.11 & 1057.55 & $<0.0001$ & $<0.0001$ \\
$\mathrm{AB}$ & 2.21 & 1 & 2.21 & 2102.26 & 0.005 & - \\
\hline
\end{tabular}

TABle 9: Correlation data analysis for the mass of brick samples.

\begin{tabular}{lcc}
\hline & Cotton dust (\%) & Mass $(\mathrm{g})$ \\
\hline Cotton dust $(\%)$ & 1 & - \\
Mass $(\mathrm{g})$ & -0.99054 & 1 \\
\hline
\end{tabular}

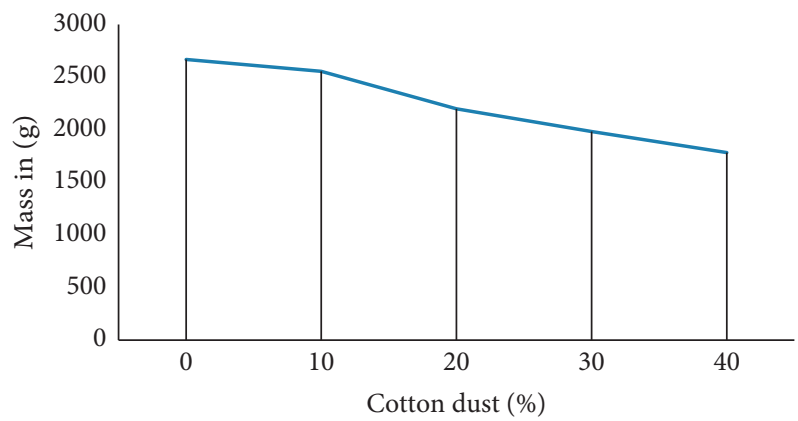

Figure 11: Effect of cotton microdust ratio on the mass of bricks.

TABLE 10: ANOVA for unit weight of bricks.

\begin{tabular}{|c|c|c|c|c|c|c|}
\hline \multirow[t]{2}{*}{ Forced terms } & \multicolumn{6}{|c|}{ A- dust and B- soil, model: linear mixture } \\
\hline & Sum of square & df & Mean square & $F$ value & $p$ value & - \\
\hline Source & 0.11 & 2 & 0.053 & 355.23 & $<0.0001$ & Significant \\
\hline & 0.10 & 1 & 0.01 & 688.29 & $<0.0001$ & - \\
\hline $\mathrm{AB}$ & $3.284 \mathrm{E}-003$ & 1 & $3.284 \mathrm{E}-003$ & 22.16 & $<0.008$ & - \\
\hline
\end{tabular}

3.5. Selected Mix Ratio. Table 12 shows the optimized selected mixing ratio. The optimization was carried out targeting to achieve maximum strength, minimum water absorption, and minimum weight. The optimized value of the bricks was achieved at $25.78 \%$ dust and $74.22 \%$ soil volume fraction. The total composite is composed of $70 \%$ matrix and $30 \%$ fibre load. 
TABLE 11: ANOVA for unit weight of bricks.

\begin{tabular}{lcccccc}
\hline Forced terms & \multicolumn{5}{c}{ Dust and soil, model: linear mixture } \\
\hline \multirow{3}{*}{ Source } & Sum of square & $\mathrm{df}$ & Mean square & F value & $p$ value prob $>p$ & - \\
& 0.051 & 1 & 0.051 & 681.3 & $<0.0001$ & $<.0001$ \\
\hline
\end{tabular}

TABLE 12: Selected ratios of mixing.

\begin{tabular}{|c|c|c|c|c|c|c|c|c|}
\hline Name & Goal & Lower limit & Upper limit & Lower wt. & Upper wt. & & Importance & \\
\hline $\begin{array}{l}\text { Dust } \\
\end{array}$ & In range & 0 & 30 & 1 & 1 & & 3 & \\
\hline Soil & In range & 70 & 100 & 1 & 1 & & 3 & \\
\hline Strength & Maximize & 6.0799 & 6.795 & 1 & 1 & & 3 & \\
\hline Absorb & Minimize & 5 & 11.2 & 1 & 1 & & 3 & \\
\hline Unit wt. & Minimize & 1.15 & 1.55 & 1 & 1 & & 3 & \\
\hline Weight & Minimize & 1.899 & 2.6599 & 1 & 1 & & 3 & \\
\hline Number & $\begin{array}{c}\text { Dust } \\
25.780\end{array}$ & $\begin{array}{c}\text { Soil } \\
74.220\end{array}$ & $\begin{array}{c}\text { Strength } \\
6.52889\end{array}$ & $\begin{array}{r}\text { Solutions } \\
\text { Abso. } \\
9.636\end{array}$ & $\begin{array}{c}\text { Unit wt. } \\
1.2199\end{array}$ & $\begin{array}{l}\text { Weight } \\
2.0876\end{array}$ & $\begin{array}{c}\text { Desirability } \\
0.56\end{array}$ & Selected \\
\hline
\end{tabular}

\section{Conclusions}

Generally, brick can be produced from different industrial wastes, and it can be used for different purposes in constructions such as for aesthetic purposes, structure unit, and fire resistance. From the finding of study, the bricks manufactured from the mix of cement, cotton waste, gravel, and sand have less compressive strength than bricks manufactured from cotton waste and soil. The observations during the tests show that the effect of $100 \%$ cotton waste does not exhibit a sudden brittle fracture even beyond the failure loads and indicates high energy absorption capacity by allowing lower labouring cost. The cotton has an effect in order to increase the water absorption of the brick, while up to $40 \%$ of cotton waste with soil is good. As the cotton waste percentage increases, the water absorption and compressive strength of the brick also increase, but the mass of the brick decreases. The microdusts are very fine and denser, so they increase the cohesiveness of the clay for brick. The bricks manufactured from soil and cotton waste have good results because they burn in order to increase their strengths. Therefore, the microdusts of cotton mixes with soil are preferable to manufacture brick. It results in a sturdy lighterweight composite having potential to be used for walls, as a wooden board substitute, economical alternative to the concrete blocks, and sound barrier panels.

\section{Data Availability}

Data will be available on request.

\section{Conflicts of Interest}

The authors declare that they have no conflicts of interest.

\section{Acknowledgments}

This work was supported by the Faculty of Textile and Fashion Technology, Aksum Institute of Technology, Aksum University, Axum, Ethiopia.

\section{References}

[1] F. F. Aspiras and J. R. I. Manalo, "Utilization of textile waste cuttings as building material," Journal of Materials Processing Technology, vol. 48, no. 1-4, pp. 379-384, 1995.

[2] J. Balasubramanian, P. C. Sabumon, J. U. Lazar, and R. Ilangovan, "Reuse of textile effluent treatment plant sludge in building materials," Waste Management, vol. 26, no. 1, pp. 22-28, 2006.

[3] G. Li, Y. Yu, Z. Zhao, J. Li, and C. Li, "Properties study of cotton stalk fiber/gypsum composite," Cement and Concrete Research, vol. 33, no. 1, pp. 43-46, 2003.

[4] B. M. Sangeetha, R. S. Murugesan, S. Atharsha, K. Saranyaa Sri, and R. Selvaraj, "Cotton dust level in textile industries and its impact on human," International Journal of Scientific and Research Publications, vol. 3, no. 4, pp. 2250-3153, 2013.

[5] P. F. Hamlyn, "Cultivation of edible mushrooms on cotton waste,” Mycologist, vol. 3, no. 4, pp. 171-173, 1994.

[6] R. K. Raju Sarakar, R. Kurar, A. Gupta, A. Mudgal, and V. Gupta, "Use of paper mill waste for brick making," Cogent Engineering, vol. 4, no. 1, 2017.

[7] M. L. Davis and D. A. Cornweel, Introduction to Environmental Engineering, McGraw Hill, New York, NY, USA, 2012.

[8] U. Nguyen Ngoc and H. Schnitzer, "Sustainable solution for solid waste management," Waste Management, vol. 29, no. 6, pp. 1982-1995, 2009.

[9] D. V. Beers, G. Corder, A. Bossilkov, and R. V. Berkel, "Industrial symbosis in the Australian minerals industry," Journal of Industrial Ecology, vol. 11, pp. 55-72, 2007.

[10] S. N. Joglekar, R. A. Kharkar, S. A. Mandavgane, and B. D. Kulkarni, "Sustainability of brick for low cost housing: a comparison between waste based bricks and burnt clay bricks," Sustainable Cities and Society, vol. 37, pp. 396-406, 2018.

[11] D. Rajput, S. S. Bhagade, S. P. Raut, R. V. Ralegaonkar, and S. A. Mandavgane, "Reuse of cotton and recycle paper mill waste as building material construction and building materials," Construction and Building Materials, vol. 34, pp. 470475, 2012.

[12] H. M. Algin and P. Turgut, "Cotton and limestone powder wastes as brick material," Construction and Building Materials, vol. 22, no. 6, pp. 1074-1080, 2008. 
[13] P. Darshan, P. Vivek, R. Viresh, S. Hardik, and V. Dipesh, "Comparsion of brick made from black cotton soil with various admixture to the normal," IJIRST -International Journal for Innovative Research in Science \& Technology, vol. 1, no. 7, 2015. 